\title{
O consumidor de terceira idade na primeira década do século XXI: uma análise da propaganda dirigida a idosos
}

\author{
The elderly consumer in the first decade of the XXI century: an \\ analysis of advertisements targeted at seniors
}

\begin{abstract}
Resumo
Este estudo adotou um método histórico qualitativo de pesquisa em marketing, para entender as diferentes visões expressas nos anúncios publicitários dirigidos aos consumidores de terceira idade na primeira década deste o século. A análise visa contribuir para o processo de interpretação do funcionamento da promoção de produtos e serviços direcionados a esse segmento. Os resultados mostram que existe uma mudança nas estratégias de comunicação dos anúncios publicitários e dos tipos de produtos dirigidos ao consumidor de terceira idade ao longo do período estudado.
\end{abstract}

Fábio Francisco de Araujo ${ }^{\mathrm{I}}$ Letícia Moreira Casotti ${ }^{2}$

Renata Céli Moreira da Silva ${ }^{3}$

Palavras-chave: Consumo, Terceira Idade, Anúncios Publicitários.

\begin{abstract}
Based on a qualitative historical approach research in marketing, the present study intends to understand the different points of view expressed in advertisements directed to the elderly consumers in the first decade of this century. The analysis contributes to the process of interpretation of the promotion of products and services targeted to this market segment. The results presents changes in the promotion strategies of advertising and changes in the types of products and services targeted for the elderly consumer over the period studied.
\end{abstract}

Keyword: Consumption, Elderly Consumer, Advertisements.

\footnotetext{
1 fabiofdearaujo@gmail.com, Brasil. Professor da Pontifícia Universidade Católica do Rio de Janeiro - PUC-Rio e da Fundação de Apoio à Escola Técnica do Rio de Janeiro - FAETEC. Doutor em Administração de Empresas pela Pontifícia Universidade Católica do Rio de Janeiro - PUC-Rio. Av. Marquês de São Vicente, 225, Gávea, CEP: 22453-900 - Rio de Janeiro, RJ - Brasil.

2 leticia@coppead.ufrj.br, Brasil. Professora da Universidade Federal do Rio de Janeiro - UFRJ. Doutora em Engenharia de Produção pela Universidade Federal do Rio de Janeiro - UFRJ. Av. Brigadeiro Tropowisk s/n, llha do Fundão, CEP: 21949900 - Rio de Janeiro, RJ - Brasil.

${ }^{3}$ renata.celi@gmail.com, Brasil. Professora da Pontifícia Universidade Católica do Rio de Janeiro - PUC-Rio. Doutora em Administração de Empresas pela Pontifícia Universidade Católica do Rio de Janeiro - PUC-Rio. Av. Marquês de São Vicente, 225, Gávea, CEP: 22453-900 - Rio de Janeiro, RJ - Brasil.

4 Ipessoa@iag.puc-rio.br, Brasil. Professor da Pontifícia Universidade Católica do Rio de Janeiro - PUC-Rio. Doutor em Letras pela Universidade Presbiteriana Mackenzie - MACKENZIE. Av. Marquês de São Vicente, 225, Gávea, CEP: 22453900 - Rio de Janeiro, RJ - Brasil.
} 


\section{Introdução}

No Brasil, com o avanço da industrialização e urbanização a partir dos anos I930, observou-se um crescimento de diversos segmentos da sociedade. Nesse momento, houve um aumento da taxa de natalidade do país, além de uma maior longevidade para população adulta, assistindo-se, assim, à formação de uma massa crescente de aposentados e pensionistas no país (BORGES, 2006). No mesmo sentido, face à tendência de envelhecimento da população brasileira (NOVAIS, 2005), começou-se a observar, nesta parcela da população, uma projeção de um grupo potencial de consumidores.

Dessa forma, o presente estudo se propôs a investigar a evolução dos anúncios direcionados ao público de terceira idade na primeira década do século XXI, buscando apontar as mudanças na abordagem do indivíduo de terceira idade e das estratégias de comunicação para promoção de produtos e serviços para consumidores desta faixa etária. Para essa análise, optou-se por consultar o acervo digital do site Propaganda em Revista e o site da Revista Veja, por serem dois canais de comunicação digital que permitem acesso facilitado a anúncios publicitários de diversos segmentos de consumidores, estando disponível e aberto para livre consulta na internet. O recorte temporal da análise foi de II (onze) anos, compreendendo os anos entre 200I e 20II, anos que abarcam a primeira década do século XXI. O site Propaganda em Revista reúne propagandas de diversas revistas por um longo período de tempo, representando um importante acervo digital de propaganda, servindo, inclusive, aos interesses de colecionadores de propagandas veiculadas em revista. Por sua vez, o site da Revista Veja reúne na íntegra as edições impressas da revista de vários anos, que são disponibilizadas na forma digital. Dessa forma, foi possível alcançar diversas propagandas dirigidas ao público de terceira idade na última década.

O artigo foi estruturado em seis seções incluindo-se esta introdução. A seção 2 apresenta a revisão de literatura. A seção 3 descreve a orientação metodológica adotada para condução do presente estudo. A análise de resultados dos anúncios publicitários direcionados aos consumidores de terceira idade é apresentada na seção 4. Na seção 5, apresenta-se uma reflexão sobre o processo de figurativização do idoso na propaganda. A seção 6 apresenta as considerações finais e, também, traz sugestões de pesquisas futuras. 
A proposta do estudo é avançar no conhecimento do tema, contribuindo para a construção de novas proposições de pesquisa.

\section{Revisão de Literatura}

A revisão da literatura apresentada a seguir dialoga com os conceitos relacionados à propaganda e contextualiza o comportamento do consumidor da população idosa no Brasil, concentrando-se nos seguintes tópicos: (i) a propaganda em revista; (ii) o mercado de consumo para terceira idade; (iii) o perfil do consumidor de terceira idade; (iv) serviços para terceira idade no Brasil.

\section{A propaganda em revista}

As empresas utilizam estratégias de comunicação de marketing para divulgar seus produtos. Diversos elementos podem compor a estratégia de comunicação de uma empresa. Segundo Kotler e Keller (20I2), esses elementos são: propaganda, venda pessoal, promoção de vendas, marketing direto e relações públicas. Para Rocha, Ferreira e Silva (20I2) o composto de comunicação envolve propaganda, promoção de vendas, relações públicas e venda pessoal.

Segundo a definição proposta por Kotler e Keller (2OI2), propaganda pode ser compreendida como uma forma paga de apresentação e promoção não pessoais de ideias, mercadorias ou serviços por um anunciante identificado. Alguns exemplos de propaganda são anúncios em TV, rádio ou impressos, anúncios em outdoors, catálogos ou propaganda na internet (ROCHA et al., 2OI2).

Dentre os anúncios impressos estão aqueles veiculados em revistas. Nesse tipo de propaganda, os profissionais de marketing devem se atentar para a ilustração e o texto a serem desenvolvidos. A ilustração é importante, pois uma imagem pode chamar a atenção de um consumidor potencial. Em relação ao texto, é fundamental ter um título que atraia o receptor da mensagem, para que ele tenha vontade de ler o restante (STREHLAU; HUERTAS, 20o6). Com efeito, conforme observa Carvalho (2002), organizadas de modo a seduzir o consumidor, as mensagens veiculadas pela propaganda impõem "nas linhas e entrelinhas, valores, mitos, ideais e outras elaborações simbólicas, utilizando os recursos próprios da língua que lhe serve de veículo (...)”. 
De acordo com o Instituto Verificador de Circulação (2OII), o número de revistas de periodicidade semanal vendidas do ano 2000 até 2010 aumentou, sendo que esse crescimento se deveu a venda de revistas avulsas e não por causa de assinaturas. Já em relação às revistas de periodicidade mensal, também ocorreu aumento de vendas, porém esse aumento se deu tanto em relação às vendas avulsas quanto por assinatura.

\section{O mercado de consumo para terceira idade}

Segundo o IBGE (2009), o envelhecimento da população é um fenômeno mundial que vem trazendo importantes mudanças na estrutura etária de diversos países. No Brasil, o envelhecimento da população ocasiona transformações em diferentes aspectos, o que impõe um olhar mais acurado para esse segmento populacional. A longevidade, principal motivo desse crescimento, está definindo os traços da população idosa brasileira. Fatores como investimento em políticas públicas de proteção ao idoso, avanços na medicina preventiva e melhoria nas condições de vida também contribuem para esse fenômeno.

Segundo levantamento da Associação Nacional das Empresas de Pesquisa de Mercado (ANEP), as classes A e B detêm a maior parcela do segmento da população de terceira idade, em menor número estão as classes D e E (ESTEVES, 20Io). Para Ballstaedt (20O7), a população de terceira idade aumenta sua expectativa de vida e como isso aumenta também a expectativa de aproveitar a vida de forma mais produtiva e saudável.

As pessoas passam por transformações à medida que envelhecem. As mudanças biológicas naturais ao envelhecimento afetam a mobilidade, a flexibilidade, a elasticidade, a força, a visão e a audição. Além disso, o aumento de idade influencia também nas relações sociais, profissionais e familiares, assim como na maneira como consomem produtos e serviços (PAK; KAMBIL, 2006).

Além disso, no geral, quando as pessoas envelhecem, passam a ter um aumento significativo da renda livre para o consumo, pois se reduzem os compromissos financeiros familiares, enquanto passam a ter mais tempo disponível para dedicar a si mesmo em função da aposentadoria (BIRTWISTLE; TSIM, 2005). Hoje, aposentados esperam continuar gastando seu dinheiro com seus interesses e necessidades, 
diferentemente das gerações anteriores que se preocupavam com a herança que deixariam para os filhos. Nesse sentido, é possível concluir que houve uma mudança do consumidor de terceira idade, pois este saiu de uma mentalidade conservadora para uma mais individualista (MYERS; LUMBERS, 2008), comportam-se de forma mais entusiasta, têm condições e desejo de comprar bens e serviços e se preocupam tanto com a aparência como em usufruir prazeres da vida (NAM et al., 2007).

De acordo com Solomon (2OII), apesar de ignorados por anos pelas grandes empresas, profissionais de marketing e pelos estudiosos acadêmicos, os idosos têm um poder econômico relevante, é preciso compreender esse público de terceira idade para entender o seu comportamento, valores e interesses. A partir dessa compreensão, as organizações podem desenvolver estratégias específicas para atrair o interesse de compra desse segmento. $\mathrm{O}$ autor sublinha ainda que há questões a serem aprofundadas dentro desse assunto, tais como a questão da idade percebida versus idade que se sente, e a questão da segmentação de grupos de idosos, o que nos remete ao fato de que há grupos distintos e com interesses específicos para cada segmento etário composto por diferentes faixas de idades da população idosa.

De fato, as pessoas da terceira idade representam consumidores com necessidades e desejos de consumo a serem satisfeitos. Assim, as empresas devem observar o aumento contingencial da população idosa e desenvolverem produtos e serviços direcionados a esse segmento da população (ESTEVES, 20IO). Segundo Giovinazzo (2008), esse segmento representa um grande mercado, tendendo a representar um mercado ainda maior nos próximos anos, com disposição para consumir produtos de acordo com suas necessidades e desejos.

Dessa forma, o envelhecimento da população brasileira abre caminho para o crescimento de um novo mercado consumidor, com características específicas e peculiares. Conforme coloca Ballstaedt (2007, p.II), "foi-se o tempo em que ser idoso era sinônimo de cadeira balanço, cestinha de tricô, mau humor e reumatismo". Ao contrário, esse segmento se mostra um mercado consumidor com valores, comportamentos, estilos de vida, bem como outras necessidades específicas. No entanto, segundo Ballstaedt (2007), a maior parte dos produtos vendidos para os idosos ainda está relacionada com a ideia de incapacidade de locomoção e/ou condição física limitada. 
Para Neder (2005), a população de terceira idade brasileira tem potencial de consumo que pode ser melhor aproveitado pelas empresas. De acordo com o autor, os pequenos empresários têm nos idosos um segmento potencial para os seus serviços, tais como academia de ginástica, de dança e yoga, agência de viagens, salão de beleza, e escolas de informática, são alguns exemplos. Já as grandes empresas têm possibilidades de explorar cosméticos, vitaminas fortificantes, viagens ao exterior, oferta de passeios em grupos como cruzeiros, restaurante com música ao vivo, shows, cursos etc.

Entretanto, as empresas que tentam criar estratégias de marketing para os consumidores de terceira idade entram em choque com o desconhecimento e as lacunas existentes sobre a população idosa enquanto consumidora (MOSCHIS, 2003). Esteves (20IO) menciona que grande parte das empresas não tem foco ou mesmo não tem interesse de oferecer produtos ou serviços direcionados para esse segmento. Segundo Moschis (2003), as empresas que lhes oferecem produtos ou serviços costumam considerar que os consumidores idosos têm as necessidades similares e os tratam da mesma forma. Para autor, mesmo as empresas que reconhecem a heterogeneidade do segmento, não sabem como dividir adequadamente esse mercado.

\section{O perfil do consumidor de terceira idade}

O comportamento do consumidor de terceira idade passou por significativas mudanças ao longo dos anos. A literatura sobre o perfil do consumidor de terceira idade frisava mais os aspectos restritivos e as limitações pelas quais este segmento de consumidores precisava enfrentar. Nesse sentido, as pesquisas em torno do consumo na terceira idade transitavam em torno das dificuldades porque passavam este grupo de consumidores em decorrência da idade. Os primeiros estudos sobre as práticas de consumo na terceira idade - assim como parte importante da literatura subsequente focavam as restrições deste grupo para realizar plenamente o seu papel de consumidor. Alexandris e Carrol (I997) relacionam tais restrições ao efeito idade e ao ciclo de vida, os quais se revelam como interferências peculiares ao contexto de decisão do consumidor. Para Fleischer e Pizam (2002), as restrições físicas e intrapessoais aumentam significativamente com a idade, pois com o avanço da idade mais deterioradas tornam-se as condições de saúde. As pessoas passam por transformações ao envelhecerem, as quais 
representam, em sua maioria, mudanças naturais ao envelhecimento (OBERG e TORNSTAM, I999). De acordo com o estudo de Hoeymans et al. (I997), as pessoas idosas tendem a perder suas habilidades funcionais com o passar dos anos, mas a saúde e a capacidade de avaliação do contexto não necessariamente diminuem com o passar do tempo. Mesmo assim, embora parte dos idosos apresente limitações físicas, não se pode generalizar essa condição para toda a população da terceira idade. No entanto, a maior parte dos produtos anunciados especificamente para os idosos ainda está relacionada à ideia de incapacidade de locomoção ou condição física limitada (Ballstaedt, 2007).

Os estudos na literatura que discutem as limitações do comportamento de consumo dos idosos debatem o assunto em diferentes perspectivas. Gilly e Zeitham (I985) estudaram a adoção de recursos tecnológicos em um grupo de terceira idade. Os resultados apontaram na direção de que os idosos têm mais dificuldades de interagir com inovações, bem como apresentam ritmo diferente para utilizar aparelhos com recursos de alta tecnologia. Já o estudo de Mattila et al. (2003) buscou conhecer o comportamento dos idosos em relação aos serviços bancários, notadamente no que diz respeito à introdução dos serviços de auto atendimento. Os resultados destes estudos mostram que os idosos sempre que possível optam por dispensar o auto-serviço e preferem ser atendidos ou assistidos por funcionários, em razão das dificuldades de interação com equipamentos automatizados. O estudo de Kennett, Moschis e Bellenger (I995) observou dificuldades parecidas em relação aos serviços financeiros disponíveis para investimento de sua renda discricionária.

Mais recentemente, Hung e Crompton (2006) pesquisaram as limitações e os benefícios associados ao uso de um parque urbano por uma amostra de idosos residentes de Hong Kong. Os pesquisadores buscaram verificar se o parque urbano dispunha de espaço adequado para lazer. Os resultados de pesquisa mostraram divergência entre os idosos. Enquanto alguns elogiaram o espaço e as atividades oferecidas, outros reclamaram da falta de limpeza, da falta de funcionários do parque e da falta de segurança no parque. Nesse sentido, foi pontuada a necessidade de algumas melhorias, pois apesar de reconhecerem sua importância, as fraquezas estruturais revelavam a necessidade de mais investimentos e cuidados para adequar o serviço à população de Terceira Idade, que requer cuidados específicos. 
Alguns estudos em marketing procuraram investigar o comportamento do consumidor de idosos. O estudo de Burt e Gabbott (r995) analisou o comportamento dessa população de consumidores em relação à compra de alimentos. Os autores observaram que os idosos eram praticamente ignorados enquanto consumidores. Esse fato foi considerado pelos pesquisadores um comportamento inadequado e ingênuo, pois não se pode ignorar a influência do no contexto familiar para compra dos alimentos consumidos pela família. Burt e Gabbott (1995) identificaram como principais fatores que impactam a escolha dos alimentos por consumidores idosos a influência da idade no estilo de vida, a relação entre as expectativas do consumidor idoso e os atributos da loja, e a relação de clientela com lojas próximas de casa.

De acordo com Solomon (2OII), em relação ao consumidor idoso, uma característica muito importante é a questão da idade percebida versus a idade real. Solomon (2OII) destaca que muitos idosos têm interesse em comprar produtos que poderiam ser destinados a consumidores mais jovens, pois para determinados grupos de consumidores idosos o consumo desses determinados bens significaria para estes a ideia de ainda estarem jovens. Segundo Moschis (2003), esse é um fenômeno muito comum, havendo uma preferência por manter o autoconceito de juventude, que leva as pessoas desses grupos a continuar observando mensagens que, em geral, são dirigidas a um público mais jovem.

Em sentido oposto, Thomas e Peters (2009) sublinham que as campanhas publicitárias devem levar em consideração a idade, pois, segundo eles, esses consumidores desejam que seus objetos de consumo sejam capazes de comunicar sua personalidade, sua geração e o grupo em que se percebem inseridos. Nesse sentido, é adequado que as ações de marketing enfatizem os produtos ou serviços, destacando sempre que possível o seu uso aos diversos segmentos etários, inclusive para a terceira idade. No entanto, no caso de produtos específicos, essa comunicação deve ser bem planejada, frisando a qualidade do que é oferecido e sua adequação para o público de terceira idade.

$\mathrm{Na}$ mesma direção, a pesquisa de Esteves (20IO) chamou atenção que a adaptação dos produtos ou serviços para esse segmento de consumidores é fundamental para satisfazer suas necessidades. Segundo a autora, a literatura existente sobre o 
assunto, embora escassa, mostra a importância desse cuidado pelas empresas. Nesse sentido, a literatura aponta para importância do "desenvolvimento de produtos e serviços específicos" e do "cuidado especial na comunicação". Sobre o "desenvolvimento de produtos e serviços específicos", Esteves (2OIO, p. 32) comenta sobre a oportunidade de se observar mercados em que essa mudança demográfica já aconteceu há mais tempo, como nos Estados Unidos e na Europa, aprendendo sobre o que foi feito para esse segmento, as adaptações realizadas, as ideias de sucesso etc. Em relação ao "cuidado especial na comunicação", Esteves (20IO) observa que a comunicação de marketing direcionada para terceira idade deve ser sempre cautelosa, pois o segmento não responde de forma favorável a propagandas de produtos para "velhos". Nesse sentido, como sugerido por Debert (1997), é adequado que as ações de marketing enfatizem os produtos ou serviços, destacando sempre que possível o seu uso aos diversos segmentos etários, inclusive para terceira idade.

\section{Serviços para terceira idade no Brasil}

De acordo com reportagem da Revista Exame publicada em abril de 2008 (STEFANO et al., 2008), a população idosa no Brasil representa um nicho de consumo específico. Grande parte dessa parcela da população recebe salário de aposentadoria ou de pensão, tendendo a direcionar seus recursos para atividades de descontratação, entretenimento e lazer. Essa faixa da população costuma se organizar em grupos para fazer festas, viajar , fazer cruzeiros, visitar parques, hospedar-se em hotel fazenda, fazer passeios individuais, em família e em grupos de terceira idade, assistir espetáculos, ir a restaurantes e participar de eventos. Além disso, eles têm muito cuidado com a saúde e com a aparência. Conforme mencionam Stefano et al. (2008), empresas como a Natura já observaram esse segmento como um grupo de consumidores potenciais e vem desenvolvendo produtos específicos para essa parte da população, como, por exemplo, uma linha específica de cremes faciais e para corpo, desenvolvidos exclusivamente para peles de mulheres acima de 80 anos.

Diferentemente do que ocorre em outras faixas etárias (ALMEIDA; GUTIERREZ, 2OO5; ARAUJO et al., 2OII; HOLT, I998; KHAN, I997; MONTEIRO, 2008; SLETTEN, 2OIO; STODOLSKA; YI, 2O03; WEININGER; LAREAU, 2009), a 
população idosa enfrenta algumas barreiras para usufruir de serviços de entretenimento e lazer, sobretudo em razão da idade avançada e de escassez de recursos financeiros (CRAWFORD; JACKSON; GODBEY, I99I). Outros estudos sugerem que o consumidor de terceira idade pode experimentar novidades nessa fase da vida, como viagens a lazer (HORNEMAN et al., 2002), convivência com amigos, independência da família, aprendizado e auto realização (GUINN, I980).

Segundo Esteves (20IO), os setores de turismo e lazer têm criado pacotes específicos para atender as demandas específicas da população de terceira idade. Várias agências de viagens estão ofertando pacotes idealizados para os interesses dos idosos. No mesmo sentido, Ladeira et al. (2003) observaram que os consumidores de terceira idade dispõem de mais tempo para viajar e usufruir de produtos turísticos.

Para Ballstaedt (2007), o lazer é o serviço que mais desperta o interesse da população de terceira idade, o que faz da diversão um ótimo negócio para esse segmento de consumidores. Segundo Nader (2005), essa fase da vida é a mais favorável para socialização entre as pessoas, tendo em vista a ausência de responsabilidade e de compromissos inadiáveis, sendo o turismo uma excelente oportunidade para preencher tais necessidades. Ainda segundo esse autor, as empresas devem entender que os idosos têm um comportamento diferente de outras gerações, razão pela qual devem lhes oferecer um produto sobre medida, visando a trazer propostas de consumo que permita a esse segmento continuar a vida depois de sua aposentadoria.

\section{Procedimentos Metodológicos}

O interesse pelos segmentos de consumidores de terceira idade é recente na literatura nacional e internacional (BALLSTAEDT, 2007; BORGES, 2006; GIOVINAZZO, 2008). Nesse sentido, o propósito deste trabalho foi o de tentar investigar as diferentes visões das empresas marcadas ao longo do tempo para esse grupo de consumidores, expressas em anúncios publicitários dirigidos aos consumidores de terceira idade. Essa análise busca contribuir para o processo de interpretação de como os consumidores idosos eram vistos pelas empresas, bem como funcionava as abordagens discursivas para promoção de produtos e serviços direcionados a esse segmento. 
O presente artigo adotou um método qualitativo de pesquisa histórica em marketing (BELK; POLLAY, I985; LE GOFF, I990; OTNES et al., 2006; WITKOWSKI; JONES, 2006), situando-se dentro de uma perspectiva interpretativista (BROWN, I997; CASOTTI, I999; THOMPSON, I997), na qual estudos podem ser construídos a partir de fatos e indícios deixados em documentos, auxiliando no entendimento de um determinado fenômeno. Esses documentos podem advir de diferentes fontes impressas, tais como registros públicos, artigos e cartas em jornais, revistas, publicações comerciais, revistas científicas, propaganda impressa, catálogos comerciais, rótulos, fotografias, entre outros (WITKOWSKI; JONES, 2006). Belk e Pollary (I985) ensinam também que as propagandas realizadas nas diversas mídias podem ser um importante recurso para análise de como um produto ou serviço oferecido ao mercado é ofertado ao longo do tempo. Essa análise contribui para perceber historicamente como um produto, serviço ou segmento no mercado se posicionavam, quais apelos eram considerados, bem como se houve mudança ao longo do tempo na forma de comunica-lo ou até mesmo na forma de dirigir ao público-alvo. Conhecer estas mudanças permite demarcar os fenômenos do consumo objeto de análise, abrindo caminho para perceber nuances relativas à: (i) alterações no comportamento do consumidor, (ii) modificações de abordagem ao segmento desejado, e (iii) observar se as propagandas foram se alterando ao considerar com mais efetividade o perfil do consumidor, valores e aspectos sociais ou culturais (BELK; POLLAY, I985). Ginzburg (1990) ensina que uma pesquisa que adota uma perspectiva histórica pode ser útil para compreender mudanças sociais e temporais, ou ainda revelar indícios sobre um determinado fenômeno. Ginzburg (I990) sublinha ainda que a pesquisa histórica pode ser considerada interdisciplinar e se alinha ao paradigma interpretativista, pois permite considerar várias perspectivas do fenômeno, interpretando-as, inicialmente, de forma fragmentada para, em sequência, reunir as informações e interpretá-las conjuntamente. Witkowski e Jones (2006) contribuem trazendo orientações de como utilizar o método de pesquisa histórica em marketing, destacando que os pesquisadores precisam construir um roteiro inicial de pesquisa como questões que serão "perguntados" às fontes. Estas questões têm o proposito de ajudar a reconstruir a trajetória do fenômeno pesquisado ao longo do tempo, proporcionando uma visão de compreensão do 
fenômeno sob a perspectiva histórica, que pode eventualmente ser analisado por meio de outros métodos.

Adicionalmente, realizou-se uma avaliação transversal dos procedimentos de figurativização (FIORIN, 20o6; GREIMAS; COURTÉS, 2008) do idoso no corpus de pesquisa. A referida analise do processo de figurativização é um dos aspectos ferramental metodológico da semiótica discursiva de linha francesa (GREIMAS; COURTÉS, 2008). Entretanto, cumpre ressalvar, para esta pesquisa, não se realizou uma análise de semiótica discursiva completa, tendo sido abordados apenas os procedimentos de figurativização.

Os anúncios foram identificados no acervo digital da Revista Veja e do site Propaganda em Revista, dois canais que oferecem anúncios publicitários para diversos segmentos, estando disponíveis e abertos para livre consulta na internet. Aleatoriamente, procurou-se em sites de busca outros anúncios sobre os principais tópicos encontrados, buscando verificar se os mesmos tópicos de propaganda eram encontrados em outros canais. O recorte temporal da análise foi de II (onze) anos, compreendido entre os anos de 200I e 2OII, período que marca o início do século XXI, momento contemporâneo ao reconhecimento da terceira idade como potencial grupo de consumidores (BALLSTAEDT, 2007; GIOVINAZZO, 2008; SOLOMON, 2OII). Assim, esse artigo se propõe avançar nesse processo, tentando contribuir para a construção de novas proposições de pesquisa sobre os consumidores de terceira idade e fornecendo pistas sobre seu respectivo interesse enquanto consumidores.

A analise de conteúdo desta pesquisa foi realizada a partir da seleção e reunião de anúncios publicitários dirigidos a população idosa. Como já informado, optou-se por privilegiar dois veículos de acervo digital disponíveis na internet que disponibilizam anúncios publicitários de um longo período de tempo, garantindo uma análise que verifica as reais gradações relacionadas a estratégias de comunicação publicitária para com esse segmento. Os veículos pesquisados permitiu reunir I69 anúncios publicitários dirigidos para o público de terceira idade.

Os anúncios publicitários examinados são heterogêneos em relação ao tipo de produto e de serviço que oferecem ao consumidor de terceira idade. Os artigos reunidos foram analisados considerando o tipo de oferta, o conteúdo e a abordagem discursivas 
utilizadas para promoção do produto ou serviço. Conforme realizado no estudo de Belk e Pollay (1985), a análise de conteúdo agrupou os anúncios permitindo criar categorias de anúncios conforme o tipo de oferta, permitindo observar a frequência de um tipo de anúncio ao longo do período analisado, bem como o desaparecimento ou o surgimento de anúncios dirigidos à população de terceira idade nas revistas examinadas. Desta forma, foi possível agrupar os I69 anúncios publicitários em 5 categorias, a saber: (I) anúncios de produtos estéticos, que reuniu 92 anúncios; (2) anúncios de produtos e serviços de cuidado com a saúde, que reuniu 25 anúncios; (3) anúncios de produtos financeiros, que reuniu 37 anúncios; (4) anúncios de serviços de atividades de lazer e recreação, que reuniu 4 anúncios, (5) anúncios de serviços educacionais, que reuniu Io anúncios.

As categorias são detalhadas e discutidas no item de resultados, apresentado a seguir.

\section{Resultados}

Segundo Belk e Pollay (1985), os anúncios publicitários são uma tentativa de despertar o interesse do consumidor para compra de um determinado tipo de produto e serviço. A publicidade pode destacar os benefícios do produto ou serviço que se quer vender ou pode despertar o interesse por meio de outros artifícios (BRAKUS et al., 2009), que podem ser representados de forma indireta ou periférica (PETTY et al. r983), motivando o consumo por meio de apelos promocionais relacionado à satisfação de consumo, destacando o prazer de ter (relacionado com a ostentação), criando necessidades (que são endossadas por ídolos do esporte, artistas, pessoas bem sucedidas etc.).

A análise empreendida permitiu observar que no início deste novo milênio, praticamente não existiam anúncios publicitários dirigidos ao segmento analisado que considerasse o seu potencial de consumo. Em geral, quando aparecia algum anúncio para o público de terceira idade estava, exclusivamente, relacionado a algum tipo de serviço médico ou estético. Outros produtos que poderiam servir a qualquer faixa etária, incluindo também este segmento, normalmente não fazem qualquer referência aos idosos, sendo normalmente utilizados nos anúncios modelos mais jovens (por exemplo, 
gilete para barbear, creme dental, perfumes, anúncio de lojas de eletrônicos, passeios turísticos etc.).

Os anúncios veiculados em 2OOI aparecem tão somente anúncios relativos a fralda geriátrica BigFral, produto estético que visa a preservar a higiene das pessoas de maior idade. Como destacado no estudo de Holbrook e Hirschman (I982), os produtos podem ser consumidos em função de seus aspectos utilitários, mas também os aspectos hedônicos podem ter um papel importante no processo de compra. Entretanto, em 2OOI, os anúncios publicitários desse produto aparecem sem nenhum apelo hedônico, destacando apenas o aspecto utilitário do produto. A propaganda, inclusive, conta apenas com a imagem da embalagem e com texto informativo sobre o produto.

Todavia, ao longo dos anos, os anúncios assumem uma nova perspectiva, incluindo uma abordagem que vai além dos aspectos utilitários dos produtos e serviços oferecidos ao público idoso, mas trazendo apelos de marketing mais intensos para despertar o interesse de consumo específico desse grupo, conforme se pode observar ao analisar as categorias de anúncios formadas neste estudo.

\section{Anúncios de Produtos Estéticos}

A categoria "produtos estéticos" reuniu 92 anúncios do total de peças analisadas. Esta categoria possui anúncios que oferecem produtos de higiene e beleza específicos para o público de terceira idade. Foi a categoria mais representativa encontrada neste estudo. A Tabela I apresenta a frequência de anúncios desta categoria no período analisado, destacados por ano. 
Tabela I: Frequência de Anúncios de Produtos Estéticos

\begin{tabular}{|c|c|}
\hline Ano & No. de Anúncios \\
\hline 2001 & 15 \\
\hline 2002 & 18 \\
\hline 2004 & 4 \\
\hline 2005 & 12 \\
\hline 2006 & 7 \\
\hline 2007 & 10 \\
\hline 2008 & 12 \\
\hline 2009 & 11 \\
\hline 2011 & 2 \\
\hline Total & $\mathbf{9 2}$ \\
\hline
\end{tabular}

Fonte: Elaborado pelos autores.

Observa-se que nos veículos analisados, não houve anúncios publicitários de produtos desta categoria nos anos de 2003 e 2010 . Os anúncios de produtos de higiene foram predominantes, tanto em quantidade como em frequência anual. Verificou-se que os anúncios de produtos de beleza específicos para terceira idade chegou a ocorrer em 2002, registrando-se um anúncio de produto de beleza, enquanto os outros dezessete anúncios encontrados nesse ano nesta categoria eram de produtos de higiene. Nos anos de 2005 e 2007 novamente surgiram anúncios de produtos de beleza, um anúncio para cada ano. Entretanto, a partir de 2009, a frequência de anúncios de produtos de higiene começa a diminuir nos veículos analisados, sendo que já não foi encontrado nenhum anúncio de produtos relacionados à higiene nos anos de 2OIO e 2OII. Em sentido oposto, os anúncios que oferecem produtos de beleza começam a ter uma frequência maior, conforme observado no ano de $20 I I$.

Além disso, os anúncios de higiene sofreram significativa modificação ao longo dos anos. Observou-se, por exemplo, que a já mencionada fralda geriátrica BigFral passou por três momentos distintos. No início, os anúncios apenas descreviam a utilidade de produto, sem investir em nenhuma outra forma de apelo promocional, as imagens se limitavam a explorar apenas a embalagem do produto. Em um segundo momento, foi introduzida a imagem do idoso, que esboçava um sorriso, mas ainda centrando a divulgação do produto em seus aspectos utilitários. Por fim, a BigFral optou por destacar imagens de idosos em momento de lazer, promovendo o produto a partir da 
diminuição de seus aspectos utilitários e aumentando seus aspectos hedônicos, considerando que o produto seria útil para que o idoso permanecesse confortável para fazer atividades de entretenimento, tais como passeios, em momento de intimidade com os parceiros, brincando com os netos etc.

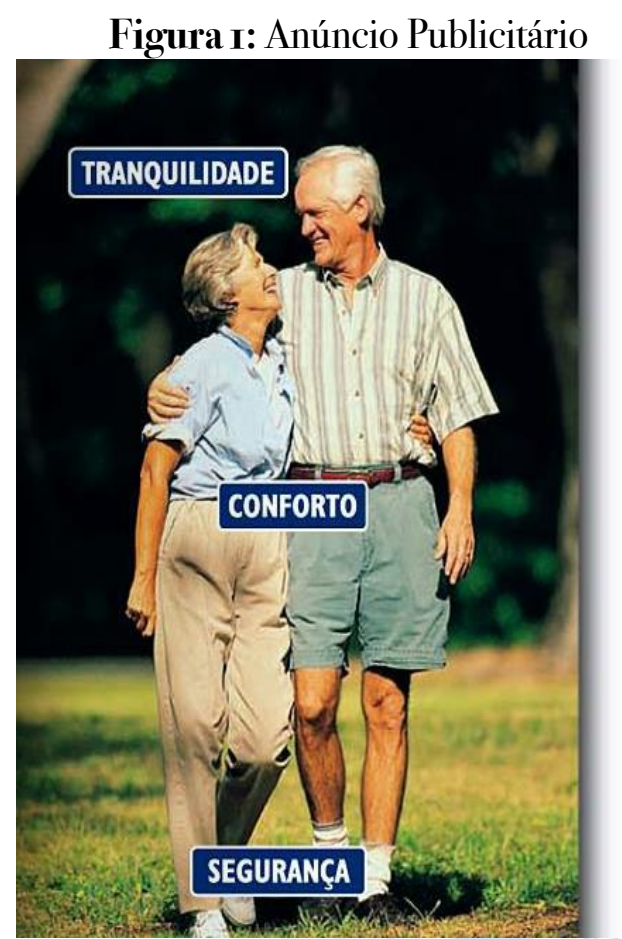

\section{BIGFRAL \\ Viva a vida}

Líder absoluta porque oferece mais conforto, mais segurança, mais absorção e mais qualidade de VIDA.

Só Bigfral tem a qualidade Pom Pom.

Fonte: Acervo Digital da Revista Veja

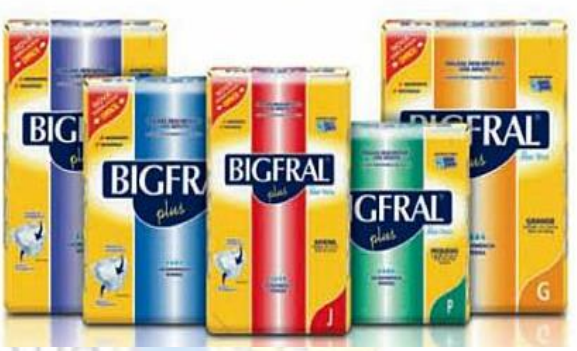

Disponível em: <http://veja.abril.com.br/acervodigital $>$

De outro lado, o aparecimento de anúncios publicitários de produtos de beleza direcionados especificamente ao público de terceira idade sugere que as empresas passaram a considerar esse público como um segmento potencial de consumo. Essa constatação vai ao encontro do que Novais (2005) e Stefano et al. (2008) observaram em suas pesquisas, quando destacaram que as empresas de cosméticos começaram a desenvolver linhas específicas para o tratamento estético de pessoas com mais idade. No mesmo sentido, Neder (2008) sublinha que a população de terceira idade tem desejos e necessidades de consumo e, geralmente, estão aposentados e possuem recursos para adquirir produtos que atendam aos seus objetivos, entre eles, comprar cosméticos e frequentar salão de beleza. 
Figura 2: Anúncio Publicitário

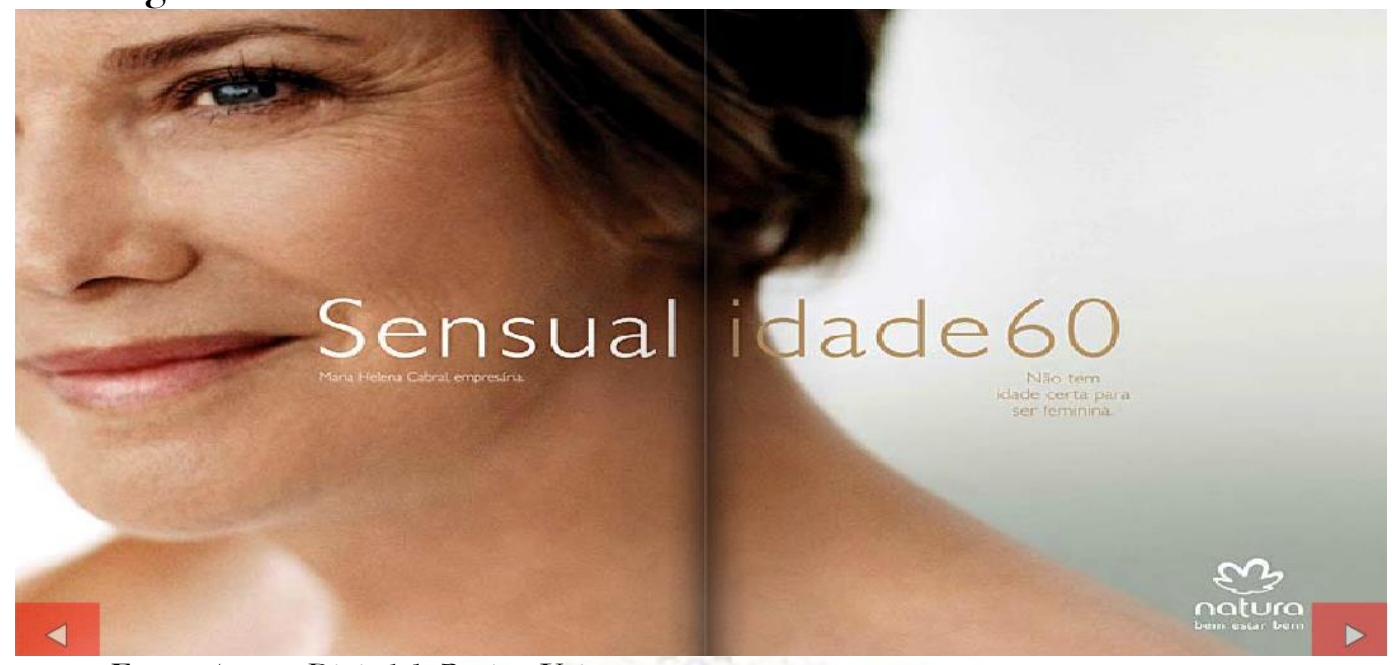

Fonte: Acervo Digital da Revista Veja

Disponível em: <http://veja.abril.com.br/acervodigital >

Anúncios de produtos e serviços de cuidado com a saúde

A categoria “produtos e serviços de cuidado com a saúde” reuniu 26 anúncios do total analisado. Esta categoria possui anúncios que oferecem produtos que visam cuidar, prevenir e tratar da saúde, tais como vitaminas e remédios. Consideraram-se também como pertencentes a esta categoria, os anúncios que ofereciam serviços de cuidados para saúde do idoso, tal como anúncios específicos de hospitais e anúncios que ofereciam serviços de atividade física especialmente desenvolvida para melhora da saúde e qualidade de vida do público idoso. A Tabela 2 apresenta a frequência de anúncios desta categoria no período analisado, destacados por ano.

Tabela 2: Frequência de Anúncios de Produtos e Serviços de Cuidado com a Saúde

\begin{tabular}{|c|c|}
\hline Ano & No. de Anúncios \\
\hline 2001 & 1 \\
\hline 2002 & 3 \\
\hline 2003 & 4 \\
\hline 2004 & 1 \\
\hline 2006 & 1 \\
\hline 2007 & 5 \\
\hline 2009 & 2 \\
\hline 2010 & 4 \\
\hline 2011 & 4 \\
\hline Total & $\mathbf{2 6}$ \\
\hline
\end{tabular}

Fonte: Elaborado pelos autores. 
A análise nos veículos utilizados para pesquisa permitiu verificar que a ampla maioria dos anúncios publicitários dirigidos à população idosa em relação aos cuidados com a saúde diz respeito, sobretudo, aos produtos e serviços médicos e farmacêuticos, que pretendem tratar da saúde do idoso. Desde o ponto inicial da análise até o ano de 2009 não foram registrados anúncios relacionados ao fomento da atividade física desse segmento. Os anúncios dessa categoria se concentram em remédios, vitaminas e serviços hospitalares.

Somente a partir de 2009, os anúncios que oferecem serviços de atividades físicas para idosos começam a aparecer, destacando a importância da prática de exercício também nesta faixa etária da vida, visando contribuir para a saúde do idoso, passando pela prevenção de determinados problemas físicos até os benefícios para o corpo que a prática de exercícios regulares pode trazer. Essa mudança de visão permitiu que fosse criado um segmento específico nas academias de ginástica, como destacado no estudo de Ballstaedt (20O7), criando um novo estilo de vida para população idosa, que passaram a fazer exercícios físicos de forma mais regular, oferecendo ocupação e estimulando o cuidado com o corpo por meio de atividades sob medida para esse grupo de pessoas. De acordo com a autora, essa atividade busca contribuir para melhor qualidade de vida, saúde e longevidade para população idosa.

Vale mencionar que remédios e serviços médicos continuam a ser anunciados para esse público, assim como os produtos estéticos da categoria anterior - como de higiene, por exemplo. Contudo, as publicidades para esses produtos e serviços passaram a ser mais ostensivas e destacam mais aspectos hedônicos. Nesse momento, em que se reconhece potencial de consumo para a população de terceira idade (GIOVINAZZO, 2008), os anúncios publicitários passaram a ser mais bem desenvolvidos pelas organizações, fato que demonstra que esse grupo de consumidores foi, enfim, enxergado pelas áreas de marketing, recebendo uma maior atenção e investimento publicitário das empresas. 


\section{Anúncios de Produtos Financeiros}

A categoria "produtos financeiros" reuniu 37 anúncios do total analisado. Esta categoria possui anúncios que oferecem propostas de investimento, condições especiais para abertura de contas, promoções e empréstimos específicos para o público de terceira idade. A Tabela 3 apresenta a frequência de anúncios desta categoria no período analisado, destacados por ano.

Tabela 3: Frequência de Anúncios de Produtos Estéticos

\begin{tabular}{|c|c|}
\hline Ano & No. de Anúncios \\
\hline 2001 & 4 \\
\hline 2002 & 3 \\
\hline 2003 & 5 \\
\hline 2004 & 5 \\
\hline 2005 & 8 \\
\hline 2006 & 5 \\
\hline 2008 & 2 \\
\hline 2009 & 4 \\
\hline 2011 & 1 \\
\hline Total & $\mathbf{3 7}$ \\
\hline
\end{tabular}

Fonte: Elaborado pelos autores.

Nos veículos que serviram de fonte para análise, os principais anúncios publicitários direcionados para idosos relacionados a produtos financeiros foram do concurso de talentos da maturidade, que visava promover os serviços de uma instituição financeira junto ao público de terceira idade. Além dessa estratégia promocional mais genérica, encontraram-se anúncios publicitários com ofertas mais específicas, tais como facilitação para abertura de conta, proposta de investimentos, entre outros. Observa-se que nos anos de 2007 e 2010 não foi registrado nenhum anúncio desta categoria nos veículos eleitos para análise.

A partir do ano de 2004, surgiram novos anúncios de bancos ofertando créditos com juros diferenciados e com desconto das parcelas do empréstimo direto na folha de pagamento (empréstimo consignado) para aposentados e pensionistas do INSS. Como mencionado no estudo de Birtwistle e Tsim (2005), grande parte da população idosa recebe salário fixo de aposentadoria ou de pensão. Borges (2006) observa que esse fenômeno também ocorre no Brasil. Assim sendo, a população de terceira idade foi 
considerada como um grupo estratégico para realização de empréstimos consignados pelos bancos, uma vez que o risco de inadimplência era minimizado pelo desconto direto na folha de pagamento (FREITAS, 2OIo).

Figura 3: Anúncio Publicitário

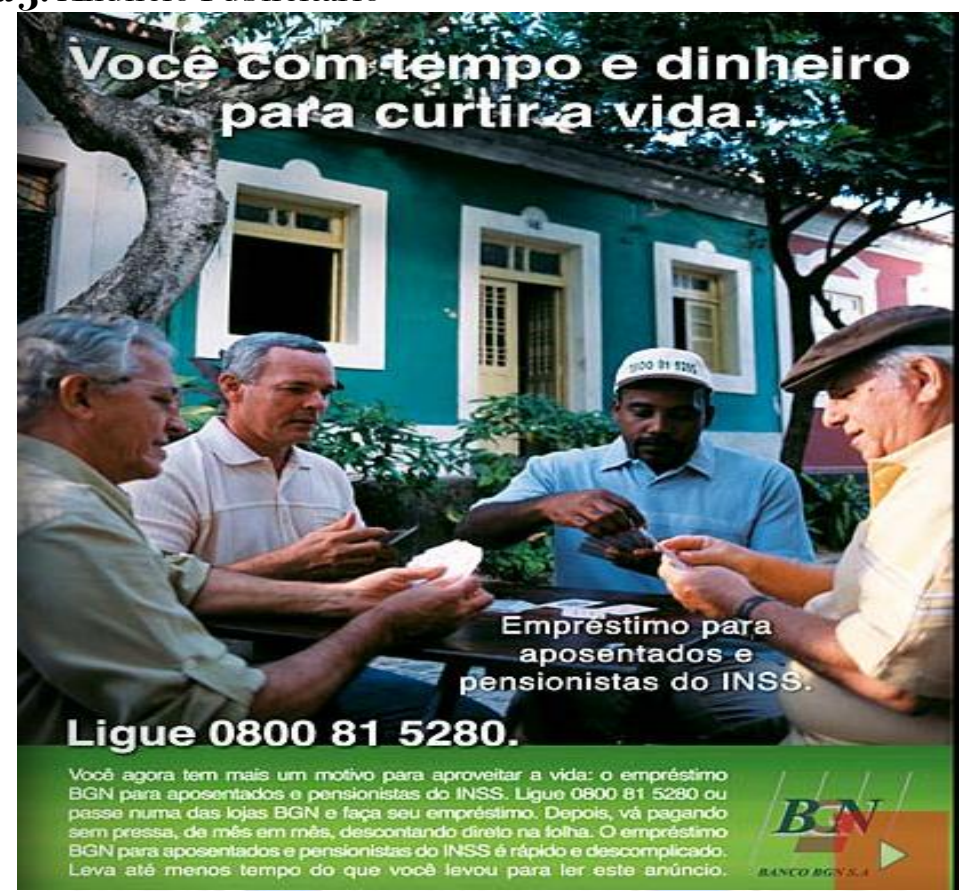

Fonte: Acervo Digital da Revista Veja

Disponível em: <http://veja.abril.com.br/acervodigital>

\section{Anúncios de Serviços de Atividades de Lazer e Recreação}

A categoria "serviços de atividades de lazer e recreação" reuniu apenas 4 anúncios do total analisado. Esta categoria possui anúncios que oferecem propostas de turismo, viagens e atividades de interação com outros idosos, pensadas especificamente para o público de terceira idade. A Tabela 4 apresenta a frequência de anúncios desta categoria no período analisado, nos veículos consultados, destacados por ano.

Tabela 4: Frequência de Anúncios de Serviços de Atividades de Lazer e Recreação

\begin{tabular}{|c|c|}
\hline Ano & No. de Anúncios \\
\hline 2008 & 1 \\
\hline 2009 & 1 \\
\hline 2010 & 2 \\
\hline Total & $\mathbf{4}$ \\
\hline
\end{tabular}

Fonte: Elaborado pelos autores. 
Esta categoria representa uma significativa mudança de visão em relação aos consumidores de terceira idade. Observa-se que durante mais da metade da primeira década, não houve nenhum anúncio publicitário dirigido a este segmente que oferecesse alguma atividade de lazer ou recreação. Somente a partir de 2008, registrou-se o primeiro anúncio que visava alcançar esse público por meio da oferta de serviços de viagem.

De acordo com Giovinazzo (2008), a população de terceira idade tem um potencial de consumo que deve ser aproveitado pelas empresas, destacando que esse segmento está em amplo crescimento no Brasil, o que significa que as empresas têm oportunidades de desenvolverem estratégias para alcançar esse grupo e, assim, ampliarem seu mercado consumidor. Esteves (2OIO), que realizou um estudo sobre a escolha do destino de viagens de pessoas de terceira idade, observou que as agências de viagens despertaram para o fato de os consumidores de terceira idade serem um excelente segmento para investir, tendo em vista que a ampla maioria já está fora do mercado de trabalho, por aposentadoria ou pensão, e, portanto, dispõe de recursos e tempo para realizar viagens. Segundo os resultados de seu estudo, Esteves (2OIO) sublinhou que, ao perceber o potencial de consumo desse grupo, as agências começaram a desenvolver pacotes de viagens com diferentes perfis para os consumidores de terceira idade, tais como: viagens de casal para pontos turísticos nacionais e internacionais; viagens de grupo para parques temáticos, viagens a hotéis fazenda, visitas a regiões religiosas e outros passeios; viagens de grupo que visa promover a sociabilidade entre pessoas da mesma faixa etária; cruzeiros marítimos para grupos de terceira idade etc. Desta forma, as empresas que operam com este tipo de serviço começaram a despertar seu interesse neste segmento, divulgando abertamente serviços de lazer direcionados para idosos, que podem ser usufruídos e consumidos individualmente, em família ou em grupos de terceira idade. 
Figura 4: Anúncio Publicitário

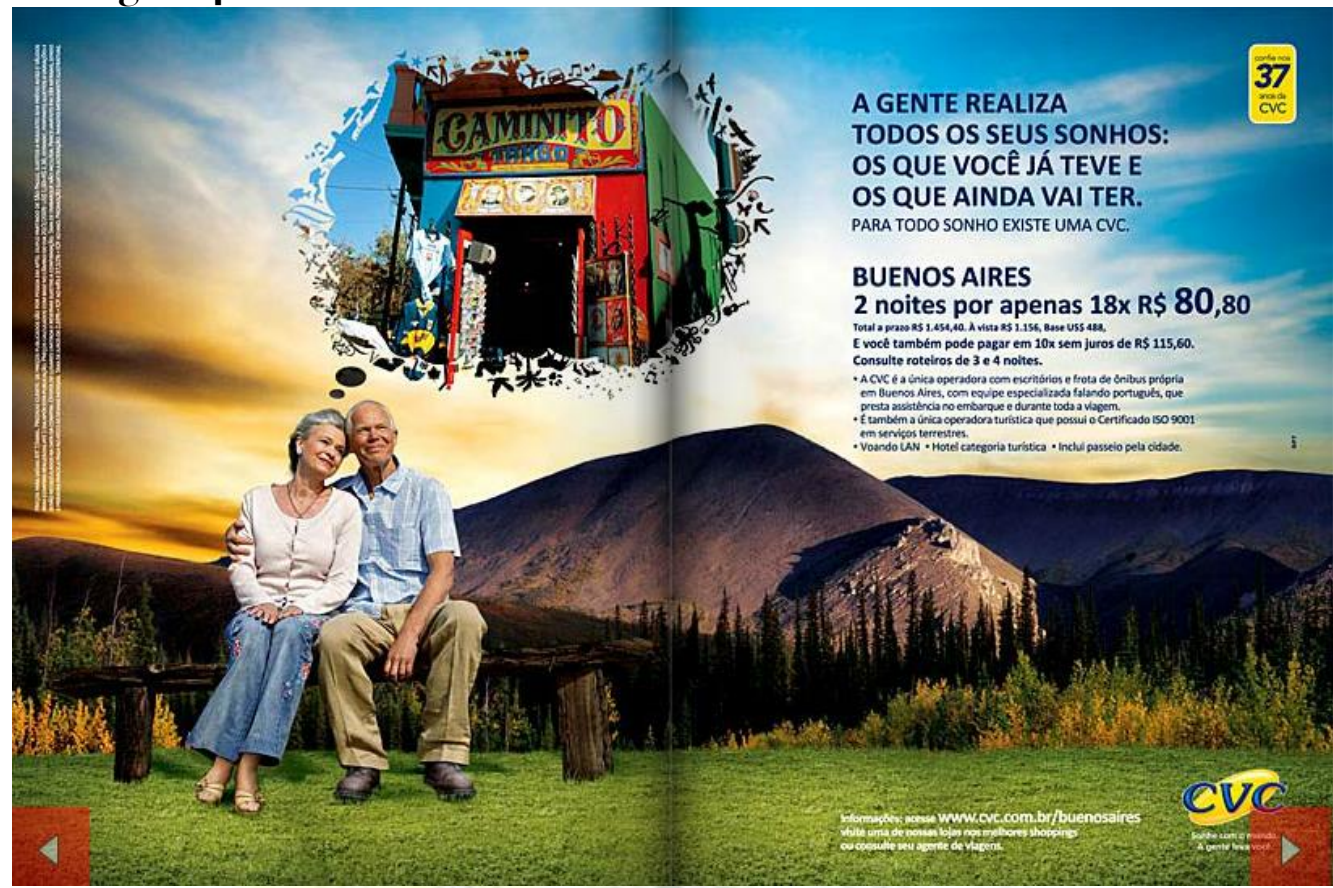

Fonte: Acervo Digital da Revista Veja

Disponível em: <http://veja.abril.com.br/acervodigital $>$

\section{Anúncios de Serviços Educacionais}

A categoria "serviços educacionais e cursos de reciclagem" reuniu Io anúncios do total analisado. Esta categoria possui anúncios que oferecem cursos de informática, línguas estrangeiras, e cursos de reciclagem em geral, desenvolvidos para pessoas de terceira idade. A Tabela 5 apresenta a frequência de anúncios desta categoria no período analisado, nos veículos consultados, destacados por ano.

Tabela 5: Frequência de Anúncios de Serviços Educacionais

\begin{tabular}{|c|c|}
\hline Ano & No. de Anúncios \\
\hline 2006 & 1 \\
\hline 2008 & 2 \\
\hline 2009 & 4 \\
\hline 2010 & 1 \\
\hline 2011 & 2 \\
\hline Total & $\mathbf{1 0}$ \\
\hline
\end{tabular}

Fonte: Elaborado pelos autores.

Esta categoria, como a anterior, demarca uma mudança na visão em relação ao público de terceira idade por parte das empresas, que o percebe claramente como um 
potencial consumidor. Nos acervos digitais consultados, o primeiro anúncio de curso destinado para terceira idade ocorre em 20o6, tratando-se de um curso de culinária. Em 2008, surgem anúncios dessa natureza com novas propostas para o segmento, como cursos para reciclagem e inclusão digital. A Figura 5, retirada da internet a partir de outro canal, corrobora uma tendência começou a se intensificar nos últimos anos: vários cursos de informática passaram a investir em turmas específicas para terceira idade.

Figura 5: Anúncio Publicitário

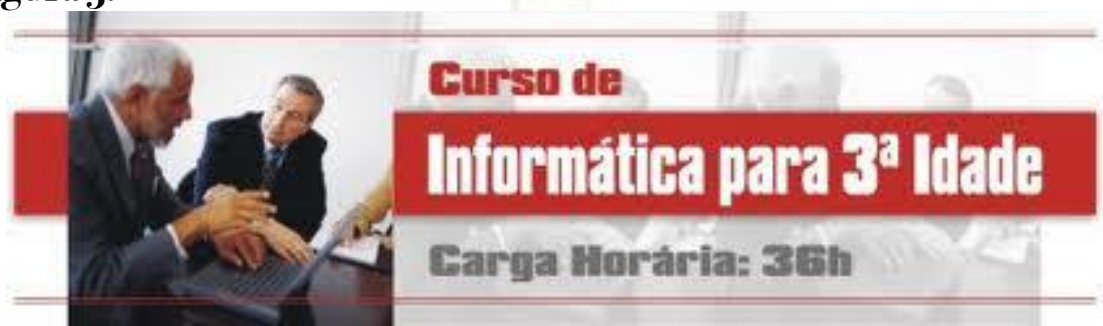

Fonte: Site da escola CompuClass Informática

Disponível em <http://www.compuclass.com.br/folhetos.asp?Curso=Terceira $>$

Nos anos seguintes, anúncios publicitários com essa proposta se intensificaram. Foram encontrados anúncios de cursos de informática destinados para os consumidores de terceira idade, no qual as empresas que oferecem serviços de ensino abriram turmas específicas para inclusão digital de pessoas idosas. Além de cursos de informática, há empresas oferecendo cursos de diferentes naturezas para idosos, tais como de atualização e reciclagem, costura, e até cursos de idioma.

Conforme Ugalde (2006) já havia mencionado, a população idosa vem se projetando como um segmento respeitável também do ponto de vista econômico, mostrando-se interessados em participar dos benefícios que o mercado de consumo oferece. Por sua vez, Neder (2005) destacou que os consumidores de terceira idade têm interesse no aprendizado, seja simplesmente para passar o tempo ou para ampliar suas capacidades, fato que faz dos cursos, das mais variadas propostas, uma excelente opção de consumo para esse público. 


\section{A Figurativização do Idoso na Propaganda}

Esta seção procura refletir sobre o processo de figurativização (FIORIN, 20o6; GREIMAS; COURTÉS, 2008) do idoso no material publicitário que serve de objeto para o presente artigo.

Ao delimitar a análise às figuras de idosos que ilustram as peças estudadas, optase por trabalhar com o nível mais concreto do discurso, no qual os esquemas narrativos abstratos dos anúncios foram revestidos de figuras que criam, sobretudo, efeitos de realidade, construindo simulacros de realidade que representam o mundo em que vivemos. Se a comunicação publicitária não apenas influencia (por "vocação"), mas, também, reflete os padrões de comportamento social (PESSÔA, 2OI3), as figuras de idosos apresentam importante insumo para a reflexão sobre o papel desempenhado pelo idoso na sociedade brasileira do início do século XXI.

A observação do corpus, independente da categorização dos anúncios por segmentos de produtos/serviços, revela que a grande maioria das imagens apresenta idosos em situação de lazer e de fruição descomprometida do tempo. Tais figuras refletem, logicamente, os temas gerais das narrativas dos anúncios que se baseiam na premissa de que a dita "terceira idade" seria o período para desfrutar das conquistas de uma vida plena de trabalho e de dedicação à família. Portanto, produtos e serviços relacionados a cuidados com a estética e a saúde, turismo e serviços financeiros (em especial oferta de crédito) surgem como soluções que auxiliam e dão suporte para a fruição do tempo.

Por outro lado, esse conjunto de figuras de idosos (em geral, ambientadas em parques, jardins e praias) colabora para a construção da imagem do idoso desvinculado do universo do trabalho e, até mesmo, das atividades e preocupações rotineiras do cotidiano. Até o próprio ato de cuidar dos netos (que pressupõe responsabilidade), não raro, é tratado de forma a infantilizar o idoso, equiparando-o à criança que seria alvo de seus cuidados e afeto, conforme o anúncio da Natura de 2005 (Figura 6), cujo texto se inicia com a frase "Meu pai e o Felipe parecem ter a mesma idade". 
Figura 6: Anúncio Publicitário

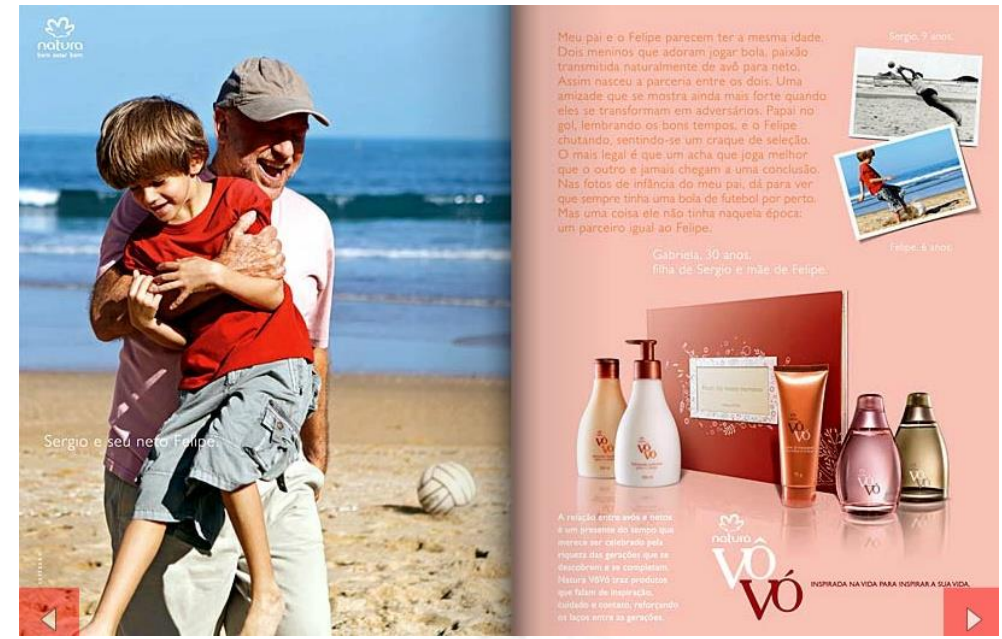

Fonte: Acervo Digital da Revista Veja

Disponível em: <http://veja.abril.com.br/acervodigital>

Raro contra-exemplo seria o anúncio da Figura 5 (anúncio de curso de informática para a terceira idade), no qual o sujeito aparece inserido em uma reunião de trabalho, a julgar pelo figurino dos participantes da cena.

Em ensaio sobre a figurativização das fases da vida na publicidade de serviços financeiros, Barros (2008) identifica que as figuras de homens de mais idade e de velhos são menos utilizadas na propaganda desse segmento, mas, quando aparecem, estão relacionadas a três temas: decadência/inatividade, experiência/competência ou, finalmente, liberdade, divertimento e ausência de obrigações ou compromissos. Já no presente artigo, não foram identificados exemplos de figurativização do idoso a serviço do tema experiência e competência nem, tampouco, da decadência. Percebeu-se claramente a concentração de imagens ao redor do tema do lazer e da ausência de compromisso.

Finalmente, pode-se dizer que as peças publicitárias analisadas apresentam uma das diversas possibilidades de representação do idoso em nossa sociedade. Nessa representação específica, se, por um lado, observa-se a construção de um quadro otimista em relação à "terceira idade" (inclusão em novas categorias de consumo, aumento da expectativa e da qualidade de vida), por outro lado, tem-se a indução a um estereótipo excludente do idoso (longe do mercado de trabalho e sem interlocutores que possam beneficiar-se de sua experiência). 


\section{Considerações Finais}

Este artigo teve como objetivo investigar a evolução dos anúncios direcionados ao público de terceira idade na primeira década do século XXI, buscando apontar as mudanças na abordagem do indivíduo de terceira idade e das estratégias de comunicação para promoção de produtos e serviços para consumidores desta faixa etária.

Apesar da crescente preocupação das Organizações em promover um contexto de ofertas mais efetivas para o consumidor da terceira idade (SOLOMON, 2OII), percebe-se a necessidade de instrumentos científicos e pesquisas acadêmicas que possam auxiliar na compreensão de como os produtos e serviços podem ser mais bem moldados para esses consumidores.

Dentre as limitações deste estudo, destaca-se o fato de a análise se concentrar em apenas dois veículos da mídia, os acervos digitais da Revista Veja e do site Propaganda em Revista (disponíveis online). Nesse âmbito, os temas específicos das categorias examinadas aqui podem ignorar o surgimento de outros temas de anúncios publicitários dirigidos para o público idoso que tenham surgido em outros veículos. Além disso, a publicidade identificada nas categorias deste estudo pode também ter ignorado o impacto cumulativo da quantidade crescente de produtos e serviços que apareceram pouco nos veículos analisados. Por exemplo, identificou-se apenas 4 anúncios na categoria "serviços de atividades de lazer e recreação", o que não significa, porém, que esta categoria foi promovida de forma tímida, como estes números sugerem, pois estas podem ter sido mais frequentes em outros espaços publicitários. Segundo Stefano et al. (2008) e Esteves (20IO), o mercado sinaliza que viagens e atividades de lazer têm sido alvos de interesse crescente pela população de terceira idade. Nesse sentido, os veículos de consulta eleitos para esse estudo que, embora oportunos e com recursos adequados para realização da análise que se pretendia empreender, podem não ter sido o principal canal de propaganda escolhido para os anúncios desta categoria. Dessa forma, foram desenvolvidas proposições que poderão ser melhor analisadas em futuros estudos contemplando ampla quantidade de mídia.

Quanto aos resultados do presente estudo, a análise empreendida permitiu observar que antes da segunda metade deste novo milênio, os anúncios publicitários dirigidos aos consumidores idosos eram raros, quase todos ofertando algum tipo de 
serviço médico ou estético (muitos relacionados à higiene). Além disso, produtos mais gerais que são úteis a qualquer faixa etária, incluindo também este segmento, normalmente são veiculados em anúncios com modelos mais jovens. No entanto, na segunda metade da primeira década do início do século XXI, sobretudo a partir do ano de 2008, intensificaram-se os anúncios publicitários direcionados para esse segmento, com propostas de consumo pensadas especificamente às pessoas de mais idades, incluindo novas categorias de produtos e serviços, que antes eram destinados exclusivamente a consumidores mais jovens. Dentro desse contexto, observou-se que as organizações voltam sua visão de forma mais expressiva para este grupo e tentam percebê-los como consumidores, os quais tinham seu potencial de consumo subaproveitado (BALLSTAEDT, 2007; NEDER, 2005; GIOVINAZZO, 2008). A análise do processo de figurativização do idoso revelou que, se esse cenário tem um lado positivo de inclusão (via consumo), por outro lado, deixa-se de vislumbrar a faceta de participação social do idoso como trabalhador ou, mesmo, como uma referência familiar de experiência e de responsabilidade. Nesse contexto, surgem as seguintes proposições para futuros estudos.

PI- Empresas que investem em produtos ou serviços para consumidores idosos estão aumentando o investimento em propagandas para esse público-alvo.

Há evidências nesses achados que sugerem uma maior ênfase na publicidade dirigida às pessoas de terceira idade. A análise dos anúncios mostra que, há poucos anos, a publicidade para esse grupo era relacionada apenas a temas instrumentais, concentrando-se em propaganda de serviços médicos e hospitalares, e em produtos de necessidades mais básicas para categoria, tais como fraldas geriátricas, remédios e vitaminas. Mais recentemente, porém, observa-se outro movimento das empresas em relação à população de terceira idade, considerando-os como potenciais consumidores. Dessa forma, surgem ofertas de produtos e serviços pensadas exclusivamente para o segmento que vão além de suas necessidades mais básicas, tais como ofertas de produtos de beleza para homens e mulheres da terceira idade, ofertas de pacotes de viagens, ofertas de passeios em grupo da mesma faixa etária, oferta de cursos para aprimoramento pessoal e outros de adaptação aos benefícios tecnológicos, oferta de atividades físicas específicas para terceira idade em academia de ginástica, entre outros. Duas outras 
proposições de pesquisa a serem investigadas em estudos futuros decorrem desta primeira.

P2- Atualmente, os anúncios publicitários voltados para o público de terceira idade tendem a enfatizar os aspectos hedônicos dos produtos ou serviços ao invés considerar apenas os aspectos utilitários.

$\mathrm{P}_{3}$ - Atualmente, existem organizações que estão repensando suas ofertas para incluir propostas específicas ao público de terceira idade.

Em termos de pesquisas futuras, um aspecto que merece maior atenção é o interesse dos consumidores de terceira idade por serviços de lazer. Seria importante refletir sobre as possibilidades de fomentar uma abordagem de caráter mais estratégico para esse segmento entre as empresas envolvidas e as instituições que têm interesse em oferecer esse tipo de atividade para este público. Esses estudos facilitariam a compreensão do equilíbrio desejável entre as ofertas de produtos e serviços para consumidores de terceira idade, permitindo observar as peculiaridades decorrentes das diferenças entre subgrupos existentes dessa faixa da população.

\section{Referências}

ALEXANDRIS, K.; CARROLL, B. An analysis of Leisure Constraints Based on Different Recreational Sport Participation Levels: Results from a study in Greece. Leisure Sciences, v. I9, n.I, p. I-I5, I997.

ALMEIDA, M.A.B., GUTIERREZ, G.L. O Lazer no Brasil: do nacional-desenvolvimentismo à globalização. Conexões, v.3, nº.I, p. 36-57, 2005.

ARAUJO, F.F.; CHAUVEL, M.A.; SCHULZE, M.F. Percepções e Significados do Lazer do Jovem de Baixa Renda: Um Estudo Exploratório em uma Comunidade da Zona Sul Carioca. In: Anais... Encontro da Associação Nacional de Pós-Graduação em Administração - ANPAD, XXXV EnANPAD. Rio de Janeiro: ANPAD, 2OII.

BALLSTAEDT, A.L.M.P. Comportamento e estilo de vida da população idosa e seu poder de consumo. In: Anais... Encuentro Latinoamericano de Diseño, II Encuentro Latinoamericano de Diseño. Universidad de Palermo, Buenos Aires, 2007.

BARROS, D.L.P.de. Exploitations stratégiques des représentations de l'âge dans les publicités bancaires. In: DARRAULT-HARRIS, I. e FONTANILLE, J. (Org.). Les âges de la vie. Paris: PUF, 2008.

BELK, R.W.; POLLARY, R.W. Materialism and Magazine Advertising during the Twentieth Century. Journal of Consumer Research, v.I2, p. 394-398, I985. 
BIRTWISTLE, G.; TSIM, C. Consumer purchasing behavior: An investigation of the UK Mature Women's Clothing Market. Journal of Consumer Behavior, v.4, p.6, p.453-464, 2005.

BORGES, A. As oscilações da classe média. ALAI, America Latina en Movimiento. 20o6. Disponível em: <http://alainet.org/active/ıI63o\&lang=es> Acesso 25.nov.20o9.

BRAKUS, J.J., SCHMITT, B.H., ZARANTONELLO, L. Brand experience: What is it? How is it measured? Does it affect loyalty? Journal of Marketing, v. 73, 2009.

BRASIL. Lei 8.842/1994. 1994. Disponível em: <http://www.planalto.gov.br/ccivil_o3/Leis/ L8842>. Acesso em I9.jun.2OII.

BROWN, S. Marketing Science in a postmodern world: introduction to the special issue. European Journal of Marketing, v. 3I, n. 3/4, p. I67-I82, I997.

BURT, S.; GABBOTT, M. The Elderly Consumer and Non-Food Purchase Behaviour. European Journal of Marketing, vol. 29, n.2, p.43-57, 1995 .

CARVALHO, N.. Publicidade: a linguagem da sedução. São Paulo: Ática, 2002.

CASOTTI, L.M. O que é a Pesquisa do Consumidor? Reflexões Geradas a Partir de um Problema Prático. In: Encontro da Associação Nacional de Pós-Graduação em Administração - ANPAD, XXIII EnANPAD. Foz do Iguaçu: ANPAD, ı999.

CRAWFORD, D.W.; JACKSON, E.L.; GODBEY, G. A Hierarchical Model of Leisure Constraints. Leisure Sciences, v. I3, p. 309-320, I99I.

DEBERT, G.G. A invenção da terceira idade e a rearticulação de formas de consumo e demandas políticas. Revista Brasileira de Ciências Sociais, v. ı2, n.34, I997.

ESTEVES, P.S. O Papel das Emoções no Processo Decisório de Escolha de Destinos de Viagens por Consumidores da Terceira Idade. Porto Alegre, 20IO. Dissertação de Mestrado. Programa de PósGraduação em Administração. Universidade Federal do Rio Grande do Sul, 20 OIO.

FLEISCHER, A.; PIZAM, A. Tourism Constraints among Israeli Seniors. Annals of Tourism Research, v. 29, n.I, p. IO6-I23, 2002.

FIORIN, J. L. Elementos da Análise do Discurso. São Paulo: Contexto, 2006.

FREITAS, R.M. A Utilização do Crédito Consignado pelos Aposentados da Terceira Idade: Um Estudo Exploratório. Pedro Leopoldo, 20IO. Dissertação de Mestrado. Programa de Pós-Graduação em Administração. Faculdades Integradas de Pedro Leopoldo, 2 OIO.

GILLY, M.C.; ZEITHAML, V.A. The Elderly Consumer and Adoption of Technologies. Journal of Consumer Research, v.I2, n.3, p. 353-357, I985.

GIOVINAZZO, R.A. Terceira idade ganhará espaço no mercado de consumo. Seminário sobre Técnica de Elaboração de Cenários. Programas de Estudos do Futuro. Faculdade de Economia e Administração. Universidade de São Paulo, 2008.

GINZBURG, Carlo. Sinais: raízes de um paradigma indiciário. In: GINZBURG, C. Mitos, emblemas, sinais: morfologia e história. São Paulo, Schwartz, r99O.

GREIMAS, A. J.; COURTÉS, J. Dicionário de Semiótica. São Paulo: Contexto, 2008.

GUINN, R. Elderly Recreational Vehicle Tourists: Motivations for Leisure. Journal of Travel Research, v.I9, n.I, p.9-I2, I980. 
HOEYMANS, N.; FESKENS, E.J.M.; VAN DEN BOS, G.A.M.; KROMHOUT, D. Age, Time, and Cohort Effects on Functional Status and Self-Rated Health in Elderly Men. American Journal of Public Health, v.87, n.IO, I997.

HOLBROOK, M.B.; HIRSCHMAN, E.C. The experiential aspects of consumption: consumer fantasies, feelings and fun. Journal of Consumer Research, v. 9, p. I32-I40, I982.

HORNEMAN, L.; CARTER, R. W.; WEI, S.; RUYS, H. Profiling the Senior Traveler: an Australian Perspective. Journal of Travel Research, v. 4I, p. 23-37, 2002.

HOLT, D.B. Does cultural capital structure American consumption? Journal of Consumer Research, v. 25, n.I, p.I-25, 1998 .

HUNG, K.; CROMPTON, J.L. Benefits and Constraints Associated with the Use of an Urban Park Reported by a Sample of Elderly in Hong Kong. Leisure Studies, v.25, n.3, p.29I-3II, 2006.

IBGE. Síntese de Indicadores Sociais: Uma análise das condições de vida da população brasileira. Estudos e Pesquisa. Instituto Brasileiro de Geografia e Estatística - IBGE. No. 26, Rio de Janeiro, 2009 .

BRASIL. Lei 8.842/1994. 1994. Disponível em: <http://www.planalto.gov.br/ccivil_o3/Leis/ L8842>. Acesso em I9.jun.2OII.

Instituto Verificador de Circulação. Disponível em: <http://www.ivcbrasil.org.br/conteudos/ pesquisas_estudos/estudo_revistas_set2OII.pdf $>$.2OII. Acesso em 08.mar.2OI4.

KENNETT, P.A.; MOSCHIS, G.P.; BELLENGER, D.N. Marketing Financial Services to Mature Consumers. Journal of Services Marketing, v. 9, n.2, p. 62-72, I995.

KHAN, N.A. Leisure and recreation among women of selected hill-farming families in Bangladesh. Journal of Leisure Research, v. 29, n.I, p.5-2O, I997.

KOTLER, P.; KELLER, K. L. Administração de Marketing: São Paulo: Pearson Education do Brasil, $2 \mathrm{OI2}$.

LADEIRA, R.; GUEDES, E.M.; BRUNI, A.L. Um Estudo do Comportamento do Consumidor Soteropolitano de Terceira Idade em Relação ao Entretenimento e Lazer com Ênfase no Turismo. In: Anais... Encontro da Associação Nacional de Pós-Graduação em Administração - ANPAD. XVII EnANPAD. Atibaia: ANPAD, 2003.

LE GOFF, Jacques. A História Nova. São Paulo: Editora Martins Fontes, r99o.

MATTILA, M.; KARJALUOTO, H.; PENTO, T. Internet Banking Adoption Among Mature Customers: Early Majority or Laggards? Journal of Services Marketing, v. I7, n.5, p. 5I4-528, 2003 .

MONTEIRO, S. Festa do consumo. São Paulo, jul. 2008. IPSOS. Disponível em $<$ http://www.ipsos.com.br> Acesso em I7.set.2009.

MOSCHIS, G. Marketing to older adults: an updated overview of present knowledge and practice. Journal of Consumer Marketing, v.2O, n.6, p.5 $5^{\mathrm{I} 6-525,2003 .}$

MYERS, H.; LUMBERS, M. Understanding older shoppers: a phenomenological investigation. Journal of Consumer Marketing, v.25, n.5, p.294-3OI, 2008. 
NAM, J.; HAMLIN, R.; GAM, H.J.; KANG, J.H.; KIM, J.; KUMPHAI, P.; STARR, C.; RICHARDS, L. The fashion-conscious behaviours of mature female consumers. International Journal of Consumer Studies, v.3I, p. IO2-IO8, 2007.

NEDER, V. O potencial de consumo da terceira idade. Jornal do Comércio. I5 de fevereiro de 2005, Rio de Janeiro/RJ, 2005.

NOVAIS, R.C. Baby Boomers na Terceira Idade, uma oportunidade de mercado: um estudo da indústria de comésticos Natura. In: Anais... Congresso Brasileiro de Ciências da Comunicação INTERCOM. 28ㅇ INTERCOM. Rio de Janeiro: INTERCOM, 2005.

OTNES, C.C.; RUTH, J.A.; LOWERY, T.M.; COMMURI, S. Capturing time. In: R.W BELK, Handbook of Qualitative Research Methods in Marketing. Cheltenham: Edward Elgar, 2006.

ONU - Organização das Nações Unidas. World population prospects: the 2006 revision. In: ONU, Population Division. Population Database. New York, 2007. Disponível em:

$<$ http://esa.un.org/unpp>. Acesso em 25.jun.2OII.

PAK, C.; KAMBIL, A. Over 50 and ready to shop- serving the aging consumer. Journal of Business Strategy, v.27, n.6, p.I8-28, 2006.

PESSÔA, L. A. G. de P. Narrativas da segurança na publicidade: um estudo semiótico. São Paulo: Editora Mackenzie, 20I3.

PETTY, R.; CACIOPPO, J.; SCHUMANN, D. Central and peripheral routes to advertising effectiveness: the moderating role of involvement. Journal of Consumer Research, v. IO, p. I35-I46, I983.

PROPAGANDA EM REVISTA. Propaganda em Revista: O maior acervo digital da propaganda. Disponível em: $<$ http://www.propagandaemrevista.com.br $>$. Acesso em I9.nov.2OII.

REVISTA VEJA. Acervo Digital da Revista Veja. Disponível em:

$<$ http://veja.abril.com.br/acervodigital/home.aspx>. Acesso em I9.nov.2OII.

ROCHA, A.; FERREIRA, J. B.; SILVA, J. F. Administração de Marketing: São Paulo: Atlas, 2012.

SLETTEN, M.A. Social costs of poverty: leisure time socializing and the subjective experience of social isolation among I3-I6-year-old Norwegians. Journal of Youth Studies, v.I3, n.3, 29I-3I5, 2 OIO.

SOLOMON, M.R. O comportamento do consumidor: comprando, possuindo e sendo. Tradução: Luiz Claudio Queiroz. $9^{\mathrm{a}}$. Edição. Porto Alegre: Bookman, $201 \mathrm{.}$.

STEFANO, F., SANTANA, L., ONAGA, M. O retrato dos novos consumidores brasileiros. Revista Exame. A.7, n. 916, 2008.

STODOLSKA, M.; YI, J. Impacts of immigration on ethnic identity and leisure behavior of adolescent immigrants from Korea, Mexico and Poland. Journal of Leisure Research, v.35, n.I, p.4979, 2003 .

STREHLAU, S.; HUERTAS, M. Z. Propaganda de Artigos de Luxo e Não de Luxo: uma Análise de Conteúdo Comparativa. In: Anais... Encontro da Associação Nacional de Pós-Graduação em Administração - ANPAD, XXX EnANPAD. Salvador: ANPAD, 2006.

THOMAS, J.B.; PETERS, C.L.O.S. Silver seniors: Exploring the self-concept, lifestyles, and apparel consumption of women over age 65. International Journal of Retail \& Distribution Management, v.37, n.I2, р.IOI8-IO4O, 2009. 
THOMPSON, C.J. Interpreting Consumers: A hermeneutical framework for deriving marketing insights from the texts of consumers' consumption stories. Journal of Marketing Research, v. XXXIV, p. $43^{8}-455$, I 997 .

UGALDE, M. Opapel das emoções no processo decisório de compra de imóveis por consumidores da terceira idade. Porto Alegre, 2006. Dissertação de Mestrado. Programa de Pós-Graduação em Administração. Universidade Federal do Rio Grande do Sul, 2006.

WEININGER, E.B.; LAREAU, A. Paradoxical pathways: an ethnographic extension of Kohn's findings on class and childrearing. Journal of Marriage and Family, v. 7I, p.680-695, 2009.

WITKOWSKI, T.H.; JONES, D.G.B. Qualitative historical research in marketing. In: R.W BELK, Handbook of Qualitative Research Methods in Marketing: Cheltenham: Edward Elgar, 2006. 